\title{
Optimization of drum drying processing parameters for production of jackfruit (Artocarpus heterophyllus) powder using response surface methodology.
}

\begin{abstract}
Response surface methodology (RSM) was used to investigate the effect of the two drum drying parameters namely steam pressure and drum rotation speed on the physicochemical properties of jackfruit powder. The quality of jackfruit powder was assessed by determining moisture content, water activity, solubility, Hunter L-, a-, b-values, Quantitative Descriptive Analysis (QDA) and hedonic test. The responses as function of independent variables studied were fitted to the second-order polynomial equations. The results indicated that both steam pressure and rotation speed of drum drastically $(\mathrm{p} \leq 0.05)$ affected the overall quality and acceptability of final product. Moisture content and water activity considerably $(\mathrm{p} \leq 0.05)$ decreased with increasing drum temperature. The desired QDA scores decreased when drum temperature was increased. The optimum drum drying process performed at $336 \mathrm{kPa}$ steam pressure, $1.2 \mathrm{rpm}$ rotation speed was recommended to provide the jackfruit powder with optimum quality.
\end{abstract}

Keyword: Jackfruit; Response surface methodology; Drum drying; Steam pressure; Drum rotation speed 